\title{
Contamination and impacts of new antifouling biocide Irgarol-1051 on subtropical coral reef waters
}

\author{
${ }^{1 *}$ M. A. Sheikh; ${ }^{1}$ T. Higuchi; ${ }^{1}$ H. Fujimura; ${ }^{1}$ T. S. Imo; ${ }^{2}$ T. Miyagi; ${ }^{1}$ T. Oomori \\ ${ }^{1}$ Faculty of Science, University of the Ryukyus, Okinawa 903-0213, Japan \\ ${ }^{2}$ Okinawa Prefectural Institute of Health and Environment, Nanjo City, Okinawa, Japan \\ Received 8 February 2009; $\quad$ revised 12 April 2009; accepted 7 May 2009: available online 1 June 2009
}

\begin{abstract}
Coral reefs are deteriorating worldwide due to various stresses, including pollution of hazardous chemicals such as antifouling chemicals. Occurrence and impacts of a new antifouling biocide Irgarol-1051 (2-methylthio4-tert- butylamino -6-cyclopropylamino -s-triazine) have been studied in coral reef waters around Okinawa Islands, Japan. The average concentration of Irgarol detected at commercial and fisheries Ports was $24.70 \pm 9.88 \mathrm{ng} / \mathrm{L}$. In Naha Bay, the average concentration of Irgarol was $10.00 \pm 12.98 \mathrm{ng} / \mathrm{L}$. The average level detected around the Ports has already approaches the environmental risk limit for the marine organisms. Irgarol was detected in waters at the frequency of $92.3 \%(24 / 26)$ of the total samples collected during two sampling campaigns (September and December, 2007) at the Ports. In Naha Bay, Irgarol was detected by 40.5 \% (17/42) of the total water samples collected monthly from Sep., 2007 to Feb., 2008, indicating that Irgarol is widely detected along the coastal shorelines of Okinawa Island. The ecotoxicological study revealed that the rate of photosynthesis in the coral Galaxea fascicularis was significantly reduced by $18 \%$ and $121 \%$ relative to control when the corals were exposed to 1000 and 10,000 ng/L of Irgarol, respectively. The calcification rate dropped by $98.3 \%$ relative to control when the corals were exposed to 10,000 ng/L of Irgarol. The results of the present study report the wide occurrence of new antifouling biocide Irgarol around coastal areas of Okinawa Island. However, the contamination does not pose serious threat on the photosynthesis and calcification of corals under short term exposure $(96 \mathrm{~h})$.
\end{abstract}

Keywords: Calcification; Photosynthesis; Pollution; PS II compounds

\section{INTRODUCTION}

Coral reef ecosystems have become vulnerable to various threats, including pollution of toxic chemicals, global environmental changes and biological survival competitions. Irgarol-1051 has been used following the legal restriction of tributyl tin (TBT) since 2003 by International Maritime Organization (IMO) (Gatidou et al., 2007). Irgarol is very effective for preventing biofoulings, however, it poses deleterious effects to non-target organisms (Karlsson and Eklund, 2004).

Irgarol is classified as a Photosystem II compound (PS II) (Jones, 2005). PS II herbicides inhibit photosynthesis and block conversion of excitation energy into chemical energy (Jones, 2005). Acute effects of Irgarol have been extensively documented on corals and other marine biota; the lowest observedeffect concentration (LOEC) of Irgarol of $60 \mathrm{ng} / \mathrm{L}$ reduced ${ }^{14} \mathrm{C}$ incorporation in the M. mirabilis (Owen et al., 2002), $50 \mathrm{ng} / \mathrm{L}$ reduced photosynthetic efficiency

ه*Corresponding Author Email: sheikhmali2003@yahoo.com Tel.: +8180 3943 8504; Fax: +8198 8958565
(F/Fm) of S. hystrix (Jones and Heyward, 2003) and 63 $\mathrm{ng} / \mathrm{L}$ reduced net photosynthesis of intact corals (Owen et al., 2002).

Following the scientific evidences of toxic behavior of Irgarol to non target organisms, already three European countries; Sweden, Denmark and the UK have restricted the use of Irgarol in antifouling paints to boats under $25 \mathrm{~m}$ (Thomas et al., 2002).

Most of the Japanese corals are found in shallow waters around Okinawa Islands. Corals in Okinawa are fringing reefs and located to the shorelines of the Island (Kayanne et al., 2004). In addition, they are adjacent to coastal areas and farms. The coral reefs around Okinawa Island are facing a threat of toxic chemical inputs from terrestrial such as domestic activities, agricultural and industrial (Kitada et al., 2008; West and van Woesik, 2001), as well as from shipping activities such as TBT (Imo et al., 2008; Sheikh et al., 2007).

Occurrence of Irgarol has been widely reported in coastal waters of Europe ( Bisselli et al., 2000; Ferrer 
and Barcelo, 2001; Gough et al., 1994; Readman et al., 1993; Tolosa et al., 1996; Zhou et al., 1996), USA (Gardinali et al., 2004; Hall et al., 2004; Owen et al., 2002; Sapozhnikova et al., 2007) and western Japan (Okamura et al., 2003; Liu et al., 1999). However, there is almost no information on occurrence and associated impacts of Irgarol- 1051 on coral reef waters around Okinawa Island (south western Japan). The only study available is on the distribution of Irgarol in river sediments in Okinawa Island (Kitada et al., 2007). In the present paper we report the contamination status of Irgarol in surface waters collected from coastal waters around Okinawa Island and the impacts of Irgarol on calcification and photosynthesis rates of coral $G$. fascicularis on the laboratory scale.

\section{MATERIALSAND METHODS}

Sampling

A total of 26 water samples were collected from commercial and fisheries ports around Okinawa Island in summer (August-September, 2008) and winter (December, 2007). Other 42 water samples were collected on monthly basis at the Naha Bay from September 2007 to February 2008.

At all stations, water samples of $4 \mathrm{~L}$ pre-cleaned amber glass bottles were dipped $(\sim 40 \mathrm{~cm})$ in the subsurface waters to avoid the sampling of surface microlayer. Environmental parameters such as temperature and $\mathrm{pH}$ were measured in situ using pH meter (Orion $290 \mathrm{~A}+$, Japan).

\section{Extraction}

Irgarol from water samples was extracted using a solid phase extraction (SPE) technique as previously reported by Owen et al., (2002) with minor modifications. Irgarol was extracted from filtered water samples using Isolute ${ }^{\circledR}$ Triazine SPE cartridges (6 mL-reservoir volume, 500 mgsorbent mass, International Sorbent Technology, IST, and EU). Prior to the extraction, each cartridge was conditioned with $10 \mathrm{~mL}$ of pesticides and PCB analysis grade methanol, followed by $10 \mathrm{~mL}$ of Milli-Q water. Water samples (2 L) were automatically passed in the solid phase cartridges using a solid phase extraction controller (Shimadzu, Japan) with the constant flow rate of 20 $\mathrm{mL} / \mathrm{min}$. A $10 \mathrm{~mL}$ of Milli-Q water was added in the cartridge at the end of each water sample extraction. Cartridges were then dried using vacuum air for about $45 \mathrm{~min}$. The cartridges were eluted with $5 \mathrm{~mL}$ of ethyl acetate: acetone $(1: 1 \mathrm{v} / \mathrm{v})$ via anhydrous sodium sulfate columns (Sep-Pak® dry, Ireland). $200 \mu \mathrm{L}$ of p-terphenyl $\mathrm{d}_{14}(50 \mu \mathrm{g} / \mathrm{L})$ obtained from Kanto Chemical Co. Inc. (Tokyo) was added as an internal standard. The combined extracts were then blown down to $200 \mu \mathrm{L}$ under gentle stream of nitrogen.

A blank was used to monitor the contamination during the whole procedure of analysis, $2 \mathrm{~L}$ of Milli Q water $(\mathrm{N}=4)$ were treated as same as the real water samples for each batch of analysis.

Recovery tests were also conducted for the purpose of monitoring the efficiency of the analytical procedure. $2 \mathrm{~L}$ water samples (collected from remote site) were spiked with known concentrations $(0 \mu \mathrm{g} / \mathrm{L}, 0.1 \mu \mathrm{g} / \mathrm{L}, 0.2 \mu \mathrm{g} / \mathrm{L}$, $0.3 \mu \mathrm{g} / \mathrm{L}, 0.4 \mu \mathrm{g} / \mathrm{L}, 0.5 \mu \mathrm{g} / \mathrm{L}$ and $1 \mu \mathrm{g} / \mathrm{L}$ ) of Irgarol donated by Ciba Specialty Chemicals Corporation (Tokyo, Japan). The samples were extracted following the same method as real water samples, including filtration step. Satisfactory results were obtained for both compounds with the average percentage recovery of $(100.45 \% \pm$ 0.14 , mean $\pm \mathrm{SD})(\mathrm{N}=4)$ for Irgarol.

\section{Chemical analysis}

Analysis of Irgarol was performed using a GC/MS (Model QP2010, Shimadzu 2005, Japan). Capillary column DB-5 MS (30 m length, $250 \mu \mathrm{m}$ was used for the compound separations. The GC was running using the following settings: Detector temp. $250{ }^{\circ} \mathrm{C}$; Column temperature $60{ }^{\circ} \mathrm{C}$; Injection temperature $250{ }^{\circ} \mathrm{C}$; temperature Program rate $60{ }^{\circ} \mathrm{C}$ (2 min.hold) $15 / \mathrm{min}$. $280{ }^{\circ} \mathrm{C}(1 \mathrm{~min}$.); Pressure $100.0 \mathrm{kPa}$. A $1 \mu \mathrm{L}$ of the extracts was injected in the GC equipped using autosampler (AOC-20is) in splitless mode. Irgarol concentrations were quantified using selected ion monitoring mode (SIM). Quantifier ions for Irgarol were m/e 253, 182 and 283, $\mathrm{m} / \mathrm{e} 244$ for internal the standard $p$-terphenyl- $\mathrm{d}_{14}$. Irgarol was confirmed by full scan mode.

\section{Eco-toxicological study}

Irgarol solutions used for exposure experiments were (0 ng/L (control), $1000 \mathrm{ng} / \mathrm{L}$ and, 10,000 ng/L).A $100 \mathrm{~mL}$ of stock solution of $1000 \mathrm{mg} / \mathrm{L}$ was prepared using acetone. Exposure concentrations were then obtained by dilution the stock solution with filtered seawater and mixed over night to get homogeneous solution.

The experiment was conducted in a continuous flow seawater aquarium $\left(15 \times 30 \times 20 \mathrm{~cm}^{3}\right)$. Seawater temperature was $27^{\circ} \mathrm{C}$ and controlled by Chiller (GXC200, China) while light intensity was controlled by a metal halide lamp (Neo Beam Light 24 W, KAMIHATA, 
Japan) which provided illumination at the coral surface at a photosynthetic active radiation (PAR) of $300 \mu \mathrm{mol}$ $\mathrm{m}^{-2} \mathrm{~s}^{-1}$ during a 12:12-h light /dark cycle, respectively. Each coral was incubated in an acryl chamber $(0.18 \mathrm{~L})$ for duration of $2 \mathrm{~h}$.

The seawater samples were collected at the beginning and at the end of incubation. The $\mathrm{pH}$ values of seawater were recorded in-situ using $\mathrm{pH}$ Meter (Orion $290 \mathrm{~A}+$, Japan). Total alkalinity (AT) was measured 0 using an auto titration system (TIM 860 Radiometer, France) within 10 days after sampling.

The rates of calcification and photosynthesis were determined by the alkalinity and $\mathrm{pH}$ depletion method (Smith, 1973; Fujimura et al., 2001).

\section{RESULTS AND DISCUSSION}

\section{Distribution}

Irgarol concentrations in water samples ranged from below detection limit $<1$ to $35 \mathrm{ng} / \mathrm{L}$ and from $<1$ to 35.1 ng/L at ports and Naha Bay, respectively.

The average concentration of Irgarol in coastal ports was $24.70 \pm 9.88 \mathrm{ng} / \mathrm{L}$. In Naha Bay, the average concentration of Irgarol was $10.00 \pm 12.98$. The relatively

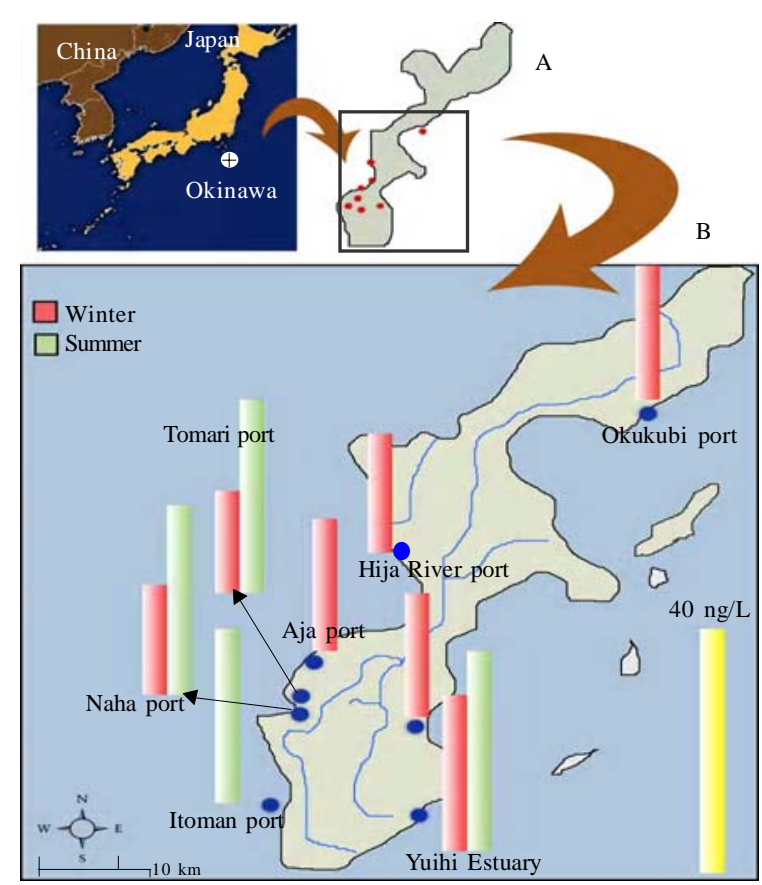

Fig. 1: Sampling maps for Irgarol; A) Location of Okinawa Island. B) Average concentrations of Irgarol around Okinawa Island; red and green bars show winter and summer seasons, respectively. high concentrations were found in the water collected from Aja Port and station 33 in Naha Bay (Fig.1).

Both stations are located at enclosed area where water exchange is limited which may enhance the elevated Irgarol concentrations (Lamoree et al., 2002). The low water exchange increases the concentration of Irgarol in water column (Albanis et al., 2002). These results are supported by previous study which revealed relatively high levels of TBT in Naha Bay at station 33 (Sheikh et al., 2007).

Spatially, the Irgarol concentrations did not vary significantly $(p>0.05)$ (Figs. 1 and 2) which may be attributed to the wide spread of Irgarol contamination around the coastal areas of Okinawa Island.

In comparison, the concentrations of Irgarol found in the coastal waters of Okinawa Island are much lower compared to those reported from various regions such as San Diego, USA 1-304 ng/L (Sapozhnikova et al., 2007); Western Japan ND-262 ng/L (Okamura et al., 2003); South Florida <1-182 ng/L (Gardinali et al., 2004); Singapore coast ND-4000 ng/L (Basheer et al., 2002); English coast <1-500 ng/L (Gough et al., 1994); coast of Spain ND-119 ng/L (Ferrer and Barcelo, 2001).

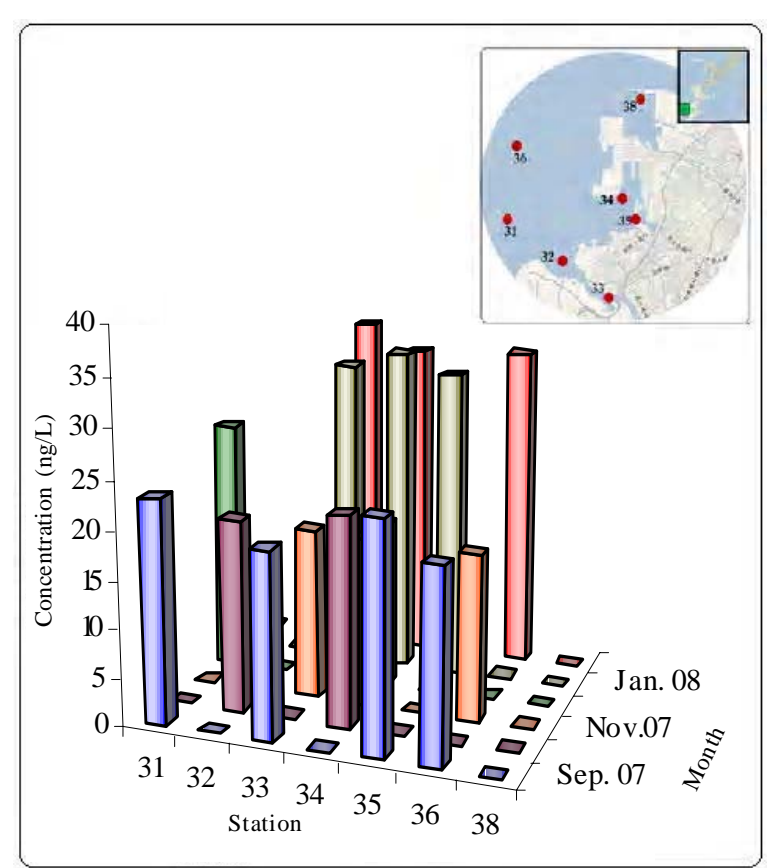

Fig. 2: Spatial and temporal distribution of Irgarol in Naha Bay (September 2007-February 2008) 


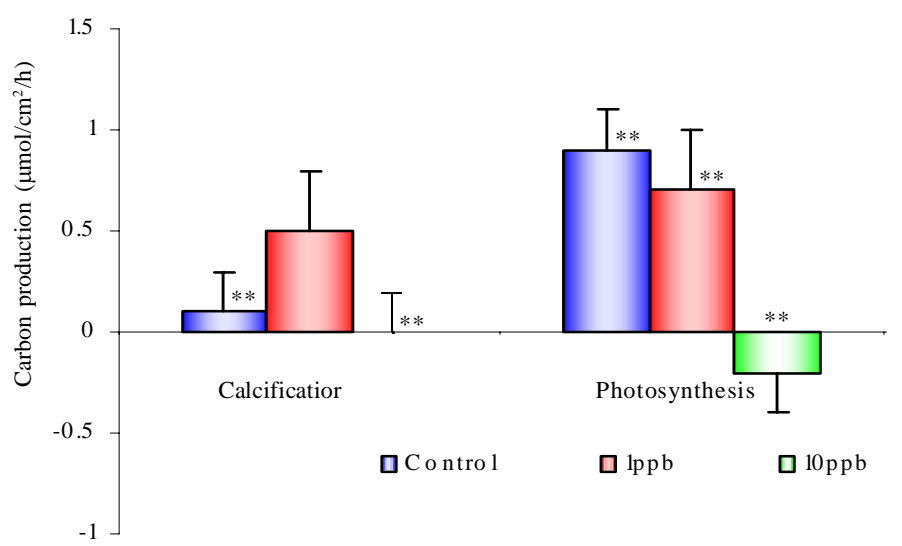

Fig. 3: Effect of Irgarol on photosynthesis rate and calcification rate of coral G. fascicularis exposed 0ng/L (control), 1000 $\mathrm{ng} / \mathrm{L}(1 \mathrm{ppb})$ and $10,000 \mathrm{ng} / \mathrm{L}(10 \mathrm{ppb})$ for $96 \mathrm{~h} .{ }^{* *}$ indicates significant at $p<0.05$

The temporal variation shows that concentration of Irgarol in ports was significantly higher $(p<0.05)$ in summer compared to winter season (Fig.1).

This is expected since the summer is the peak of season of boating activities than winter in Okinawa. The similar trend has been observed in other studies in Europe (Albanis et al., 2002; Biselli et al., 2000) and Chesapeake Bay, USA (Hall et al., 2004). No clear temporal trend has been observed for the samples collected form Naha Bay.

van Wezel and van Vlaadingen (2004) have demonstrated that the environmental risk limit (ERL) for dissolved Irgarol in coastal waters is estimated as $24 \mathrm{ng} / \mathrm{L}$, which presents a potential risk to the species and ecosystem functioning. Results show that the average concentration of Irgarol $(24.70 \pm$ 9.88) $(\mathrm{N}=26)$ is similar to the proposed ERL suggesting the possibility of posing some environmental risk in coastal waters and accompanied organisms around Okinawa Island. Additionally, $57.7 \%(15 / 26)$ of the total water samples collected from ports exceeded the maximum permissible concentration of Irgarol set by Dutch authorities (24 ng/L) (Lamoree et al., 2002).

\section{Laboratory exposure}

Photosynthesis rate of G. fascicularis was significantly reduced when exposed to both treatments of Irgarol (1000 and 10,000 ng/L) (ANOVA $p<0.05$ ) (Fig.3). In comparison to the control corals, the photosynthesis rate of exposed corals was dropped by $18 \%$ and $121 \%$ for 1000 and 10,000 ng/L, respectively. Complete inhibition of photosynthesis was observed when corals were exposed to Irgarol of concentration 10,000 ng/L (Fig. 3).

Results reveal that the photosynthesis rate gradually decreased when corals were exposed to treatments of 1000 and 10, $000 \mathrm{ng} / \mathrm{L}$ of Irgarol. These results are supported by the previous studies by Jones and Heyward, (2003) and Owen et al. (2002) which also showed that Irgarol inhibits the photosynthesis of corals by blocking conversion of excitation energy into chemical energy (Jones, 2005). Irgarol inhibits photosynthesis by blocking the electron transport in phosystem II (PSII), eventually leads disruption in the symbiosis between zooxanthellae and host coral (Raberg et al., 2003). Irgarol can disrupt photosynthetic electron flow eventually leading to loss of excitation energy at Photosynthetic Reaction Center (Jones and Kerswell, 2003).

Significant reduction of calcification was observed in this study when corals G. fascicularis were exposed to the Irgarol treatment of $10,000 \mathrm{ng} / \mathrm{L}$ (ANOVA $\mathrm{p}<$ 0.05 ), while the treatment of $1000 \mathrm{ng} / \mathrm{L}$ Irgarol did not show significant effect on calcification rate to the exposed corals (ANOVA $p>0.05$ ) (Fig. 3). The calcification rate was reduced by $98.3 \%$ relative to control treatment, when corals exposed to $10,000 \mathrm{ng} /$ L Irgarol. 
Calcification of corals is controlled by a mutualistic relationship with zooxanthellae. The zooxanthellae utilize the waste product of a host such as $\mathrm{CO}_{2}$ from respiration. This study demonstrates that at 10,000 $\mathrm{ng} / \mathrm{L}$ treatment of Irgarol caused sharp decrease in calcification of G. fascicularis. This might be caused by the disruption of symbiosis between zooxanthellae and the host coral. Irgarol might also block the energy which may be needed to trigger calcium uptake from seawater coeleteron of G. fascicularis (Al-Horani et al., 2003). It was suggested that the deterioration of calcification rate might be caused by the blockage of energy by the PSII compounds. Energy is needed for the calcification process to transport ions and for the formation of organic matrix (Chalker and Taylor, 1975).

The contamination results obtained from this study shows that the levels of Irgarol found in the coastal shoreline around Okinawa Island are far lower than the effective levels and seem not posing serious threat to the carbon metabolisms of sclerectenian corals such as G. fascicularis under short term exposure.

Previous studies showed that the lowest observedeffect concentration (LOEC) of Irgarol of $\sim 60 \mathrm{ng} / \mathrm{L}$ may reduce ${ }^{14} \mathrm{C}$ incorporation in the M. mirabilis (Owen, 2002), $50 \mathrm{ng} / \mathrm{L}$ may reduce F/Fm' of S. hystrix (Jones and Heyward, 2003), none of the water samples in this study has exceeded the toxicological end point. However, it is evident that the maximum level of Irgarol ( $35 \mathrm{ng} / \mathrm{L}$ ) found in this region seemed to be in the same order of magnitude of the effective concentration ( 60 $\mathrm{ng} / \mathrm{L}$ ). Close monitoring of Irgarol contamination around this region remains important. It should be also taken into account the possibility of the detected levels of Irgarol to induce the chronic and synergistically effects to corals and other saltwater organisms such as Macrophyta E. intestinalis (Scarlett et al., 1997).

Contamination of new antifouling biocide Irgarol is prevalent in the coastal areas around the coral reef waters in Okinawa Island. However, at present it does not impose serious impact on the survival of reef building corals.

\section{ACKNOWLEDGEMENTS}

The most sincere appreciation is due to Ciba Specialty Chemicals Corporation (Tokyo, Japan) for providing the Irgarol-1051 standard. Apart of this study was financially supported by the Japan Society for the Promotion of Science (JSPS) for awarding the principal author a postdoctoral fellowship for foreign researcher.
The authors are also grateful to Mr. Armid and Ms Fahmiati for their help on alkalinity measurements.

\section{REFERENCES}

Albanis, T. A.; Lambropoulou, D. A.; Sakkas, V. A.; Konstantinou, I. K., (2002). Antifouling paint booster biocide contamination in Greek Marine sediments. Chemosphere. 48 (5), 475-485 (11 pages).

Al-Horan, F. A.; Al-Moghrabi, S. M.; De Beer, D., (2003). The mechanism of calcification and its relation to photosynthesis and respiration in the scleractinian coral Galaxea fascicularis. Mar. Biol., 142 (3), 419-426 (8 pages).

Basheer, C.; Tan, K. S.; Lee, H. K., (2002). Organotin and Irgarol-1051 contamination in Singapore coastal waters. Mar. Pollut. Bull., 44 (7), 697-703 (7 pages).

Biselli, S.; Bester, K.; Hühnerfuss, H.; Fent, K., (2000). Concentrations of the antifouling compound Irgarol 1051 and of organotins in water and sediments of German North and Baltic Sea marinas. Mar. Pollut. Bull., 40 (3), 233243 (11 Pages).

Chalker, D. J.; Taylor, D. L., (1975). Light enhanced calcification, and the role of oxidative phosphorylation in calcification of coral Acropora cervicornis. P. Roy. Soc. Lond. B. Biol., 190 (1100), 323-331 (9 pages).

Ferrer, I.; Barceló, D., (2001). Identification of a new degradation product of the antifouling agent Irgarol 1051 in natural samples. J. Chromatogr. A., 926 (1), 221-228 (8 pages).

Fujimura, H., Oomori, T., Maehira, T., Miyahira, K. (2001).Change of coral carbon metabolism influenced by coral bleaching. Galaxea, 3, 41-50 (10 pages).

Gardinali, P. R.; Plasencia, M. D.; Maxey, C., (2004). Occurrence and transport of Irgarol 1051 and its major metabolite in coastal waters from South Florida. Mar. Pollut. Bull., 49 (11-12), 1072-1083 (12 pages).

Gatidou, G.; Thomaidis, N. S.; Zhou, J. L., (2007). Fate of Irgarol 1051, diuron and their main metabolites in two UK marine systems after restrictions in antifouling paints. Environ. Int., 33 (1), 70-77 (8 pages).

Gough, M. A.; Fothergill, J.; Hendrie, J. D., (1994). A survey of southern England coastal waters for the s-tria- zine antifouling compound Irgarol 1051. Mar. Pollut. Bull., 28 (10), 613-620 (8 pages).

Hall, Jr. L. W.; Killen, W. D.; Gardinali, P. R., (2004). Occurrence of Irgarol 1051 and its major metabolite in Maryland waters of Chesapeake Bay. Mar. Pollut. Bull., 48 (5-6), 554-562 (9 pages).

Imo, S. T.; Sheikh, M. A.; Sawano, K.; Fujimura, H.; Oomori, T., (2008). Distribution and possible impacts of toxic organic pollutants on coral reef ecosystems around Okinawa Island, Japan. Pac. Sci., 62 (3), 317-326 (10 pages).

Jones, R., (2005). The ecotoxicological effects of Photosystem II herbicides on corals. Mar. Pollut. Bull., 51 (5-7), 495-506 (12 pages).

Jones, R. J.; Heyward, A. J., (2003). The effects of Produced Formation Water (PFW) on coral and isolated symbiotic dinoflagellates of coral. Mar. Freshwater Res. 54 (2), 1-10 (10 pages). 
Jones, R. J.; Kerswell, A. P., (2003). Phytotoxicity of Photosystem II (PSII) herbicides to coral. Mar. Ecol. Prog. Ser., 261, 149-159 (11 pages).

Karlsson, J.; Eklund, B., (2004). New biocide-free anti-fouling paints are toxic. Mar. Pollut. Bull., 49 (5-6), 456-464 (9 pages).

Kayanne, H.; Hongo, C.; Yamano, H., (2004). Coral reef landforms in Japan. In: Ministry of the Environment and Japanese Coral Reef Society (Ed.). Coral Reefs of Japan. Ministry of the Environment, Tokyo, Japan, 14-19

Kitada, Y.; Kawahata, H.; Suzuki, A.; Oomori, T., (2008). Distribution of pesticides and bisphenol A in sediments collected from rivers adjacent to coral reefs. Chemosphere, 71 (11), 2082- 2090 (9 pages).

Lamoree, M. H.; Swart, C. P.; van der Horst, A.; van Hattum, B., (2002). Determination of diuron and antifouling paint biocide Irgarol 1051 in Dutch Marinas and coastal waters. J. Chromatogr. A., 970 (1-2), 183-190 (8 pages).

Liu, D.; Pacepavicius, G. J.; Maguire, R. J.; Lau, Y.; Okamura, H.; Aoyama, I., (1999). Survey for the occurrence of the new antifouling compound Irgarol 1051 in the aquatic environment. Water Res., 33 (12), 2833-2843 (11 pages).

Okamura, H.; Aoyama, I.; Ono, Y.; Nishida, T., (2003). Antifouling herbicides in the coastal waters of western Japan. Mar. Pollut. Bull., 47 (1-6), 59-67 (9 pages).

Owen, R.; Knap , A.; Toaspern, M.; Carbery, K., (2002). Inhibition of coral photosynthesis by the antifouling herbicide Irgarol 1051. Mar. Pollut. Bull., 44 (7), 623-632 (10 pages).

Raberg, S.; Nyström, M.; Erös, M.; Plantman, P., (2003). Impact of the herbicides 2, 4-D and diuron on the metabolism of coral porites cylindrica. Mar. Environ. Res. 56 (4), 503514 (12 pages).

Readman, J. W.; Kwong, L. L. W.; Grondin, D.; Bartocci, J.; Villeneuve, J. P.; Mee, L. D., (1993). Coastal water contamination from a triazine herbicide used in anti- fouling paints. Environ. Sci. Tech., 27 (9), 1940-1942 (3 pages).

Sapozhnikova, Y.; Wirth, E.; Schiff, K.; Brown, J.; Fulton, M.,
(2007). Antifouling pesticides in the coastal waters of Southern California. Mar. Pollut. Bull., 54 (12), 1972-1978 (7 pages).

Scarlett, A.; Donkin, M. E.; Fileman, T. W.; Donkin, P., (1997). Occurence of the marine antifouling agent Irgarol 1051 within the plymouth sound locality implications for the green macroalga Enteroporpha intestinalis. Mar. Pollut. Bull., 34 (8), 645-651 (7 pages).

Sheikh, M. A.; Keiko T.; Xiaochun, W.; Kenzaburo, S.; Sia, T. I.; Oomori, T., (2007). Spatial and seasonal behaviour of organotin compounds in protected subtropical estuarine ecosystems in Okinawa, Japan. Int. J. Environ. An. Ch., 87 (12), 847-861 (15 pages).

Smith, S. V., (1973). Carbon dioxide dynamics:A record of organic production, respiration, and calcification in the Eniwetok reef flat community. Limnol. Oceanogr., 18 (1), 106-120 (15 pages).

Thomas, K. V.; McHugh, M.; Waldock, M., (2002). Antifouling paint booster biocides in UK coastal waters: input, occurrence and environmental fate. Sci. Total. Environ., 293 (1-3), 117-127 (11 pages).

Tolosa, I. J.; Readman, W.; Blaevoet, A.; Ghilini, S.; Bartocci, J.; Horvat, M., (1996). Contamination of Mediterranean (Cote d'Azur) coastal waters by organo-tins and Irgarol 1051 used in antifouling paints. Mar. Pollut. Bull., 32 (4), 335341 (7 pages).

van Wezel, A. P.; van Vlaardingen, P., (2004). Environmental risk limits for antifouling substances. Aquat. Toxicol., 66 (4), 427-444 (18 pages).

West, K.; van Woesik, R., (2001). Spatial and temporal variance of river discharge on Okinawa (Japan): Inferring the temporal impact on adjacent coral reefs. Mar. Pollut. Bull., 42 (10), 864-872 (9 pages).

Zhou, J. L.; Fileman, T. W.; Evans, S.; Donkin, P.; Mantoura, R. F. C.; Rowland, S. J., (1996). Seasonal distribution of dissolved pesticides and polynuclear aro-matic hydrocarbons in the Humber Estuary and Humber coastal zone. Mar. Pollut. Bull., 32 (8-9), 599-608 (10 pages).

\footnotetext{
AUTHOR (S) BIOSKETCHES

Sheikh, M. A., Ph.D., JSPS postdoctoral fellow, Department of Chemistry, University of the Ryukyus, Okinawa, Japan. Email: sheikhmali2003@yahoo.com

Higuchi, T., Ph.D., Postdoctoral research fellow, Department of Chemistry, University of the Ryukyus, Okinawa, Japan. Email: h098480@sci.u-ryukyu.ac.jp

Fujimura, H., Ph.D., Assistant professor, Department of Chemistry, University of the Ryukyus, Okinawa, Japan.

Email: fujimura@sci.u-ryukyu.ac.jp

Imo, T., Ph.D., Lecturer, Faculty of Science, Samoa National University, Samoa, Japan. Email: taema.imo@gmail.com

Miyagi, T., M.Sc., Chief of Environmetal sciences, Okinawa Prefectural Institute of Health and Environment, Nanjo city, Okinawa, Japan. Email: miyagto@pref.okinawa.lg.jp

Oomori, T., Ph.D., Professor, Department of Chemistry, University of the Ryukyus, Okinawa, Japan. Email: oomori@sci.u-ryukyu.ac.jp
} 